\title{
Importance of Extensive Sampling Methodology on the Pick up Rate of Involvement of Nipple Areola in Carcinoma Breast
}

\author{
Sumanashree Mallappa*, Arti Khatri, Nimisha Sharma and Uma Sharma \\ Department of Pathology, VMMC \& Safdarjung Hospital, New Delhi, India
}

\section{ABSTRACT}

Background: Breast cancer is the leading cause of death from cancer for females 40-44 years of age which is responsible for $19 \%$ of cancer related death in women. The exact percentage of NAC involvement in breast carcinoma cases depends on many parameters. Grossing methodology used can influence the pick up rate of carcinoma involvement in nipple areolar region in cases of carcinoma breast.

Methods: Aim of the study was to compare the pick up rate of involvement of nipple areola complex in carcinoma breast cases by extensive nipple areolar sampling vs routine methodology.

We studied 30 cases of breast carcinomas using extensive sampling methodology and compared the results with routine sectioning method. All the cases were having grossly uninvolved nipple areolar complex.

Chisquare test was used to know if there was an association between the grossing technique and positivity rate of nipple areolar complex. Chi-square table was prepared and statistics was calculated using SPSS software.

Result: There was a statistically significant association between the grossing methodology and pick up rate of nipple areolar involvement in carcinoma breast.

Conclusion: Our findings showed that, if Only gross involvement of nipple is taken into consideration large amount of occult NAC involvement will be missed out, which can be picked up only by extensive sampling of NAC. Increase in the accuracy of involvement of nipple areolar complex can further guide in the treatment of breast carcinoma cases by nipple sparing mastectomy.

Keywords: Breast Carcinoma, Grossing Technique, Occult Lesion, Nipple Sparing Mastectomy, Comparison Of Methods

\section{Introduction}

Breast cancer is the most common cancer in women both in the developed and the developing world. The incidence of carcinoma breast is increasing in the developing world due to increase life expectancy, increase urbanization and adoption of western lifestyles ${ }^{1}$ Carcinoma breast is the most common cancer in women worldwide. Nearly 1.7 million new cases were diagnosed in 2012 (second most common cancer overall). This represents about $12 \%$ of all new cancer cases and $25 \%$ of all cancers in women. ${ }^{2}$ Many studies have been done to know the incidence rate of involvement of nipple areola in cases of carcinoma breast with percentage involvement according to the studies ranging from $0 \%$ to $58 \%{ }^{3-6}$. In all the studies yielding a higher percentage of involvement, multiple sections were taken instead of traditional one vertical section ${ }^{4,6}$.

Grossing methodology used can influence the pick up rate of carcinoma involvement in nipple areolar region in cases of carcinoma breast. Nipple areola involvement can be due to direct extension of primary tumour, dissemination by way of ducts or malignant changes independent of primary tumour ${ }^{7}$. Pathologically mechanism of spread can be of 3 types- direct extension, dissemination through ducts and lymphatics ${ }^{8}$.

Routinely during grossing of mastectomy specimens, one vertical section is taken from the nipple areolar region and submitted. In cases where there is gross involvement of nipple and areola the entire nipple areolar region is submitted by taking multiple sections ${ }^{9,10}$ In our study even while nipple and areolar region was grossly uninvolved we took multiple sections and extensive sampling methodology was followed.

Hence we followed extensive sampling technique, as the traditional one sagittal section is likely to underestimate NAC involvement. Aim of the study was to compare the pick up rate of involvement of nipple areola complex in carcinoma breast cases by extensive nipple areolar sampling vs routine methodology.

\section{Materials and Methods}

A prospective study was done on a total of 30 mastectomy specimens between 2011 and 2013. The study was carried out in Department of Pathology, Vardhman Mahavir 
Medical College and Safdarjung Hospital, New Delhi. Ethical clearance for the study was taken from the ethical committee VMMC \& Safdarjung hospital New Delhi. Before the study was done all cases were also examined by routine grossing technique of taking one vertical section.

We followed an extensive NAC sampling method and excluded cases with clinically evident NAC involvement. All mastectomy specimens were grossly examined bread loafing methodology was followed and serial sectioning was done with thickness not greater then $1 \mathrm{~cm}$. Nipple areolar complex was divided into 4 quadrants. From each quadrant, saggittal section was taken from nipple papilla and horizontal sections were taken from areolar and subareolar region. Thus a total of 12 blocks were made from nipple areolar region for each mastectomy specimen(Fig. 1).

Each quadrant was divided into 3 levels.

Level 1- Nipple papilla,

Level 2- Areola,

Level 3- Retroareolar region

Hematoxylin and eosin staining was done on paraffin sections and the slides were examined microscopically.
Results were compared with the routine grossing methodology and the performance of both methods for the pick up rate of nipple raeolar involvement in carcinoma breast was assessed. Tumour- NAC was recorded in all cases to assess its importance as a predictor of nipple areolar involvement.

\section{Result}

In routine grossing method- 6/30 cases showed nipple areolar involvement, while in extensive sampling method 15/30 cases showed nipple areolar involvement (Fig 2,3,4 and 5). 9 cases with nipple areolar involvement was missed by routine method where in only one vertical section was taken and in all the cases, nipple areola were grossly uninvolved(Table-1).

Chi-square test was used to know if there was an association between the grossing technique and positivity rate of nipple areolar complex (Table 2). Chi-square table was prepared and statistics was calculated using SPSS software. The chisquare statistic value is 5.9341 . The $\mathrm{p}$ - value is 0.014851 . This result is significant at $\mathrm{p}<0.05$ (Table 2).

Table-1

\begin{tabular}{|c|c|c|c|c|c|}
\hline Cases & Levels involved & Skip lesion & $\begin{array}{l}\text { Routine grossing } \\
\text { method }\end{array}$ & $\begin{array}{l}\text { Our grossing } \\
\text { method }\end{array}$ & $\begin{array}{c}\text { Tumour Areola } \\
\text { Distance (in cm) }\end{array}$ \\
\hline 1 & NONE & Nil & Negative & Negative & 5 \\
\hline 2 & 2B & Present & Negative & Positive & 3 \\
\hline 3 & 1B,1C,4B & Nil & Positive & Positive & 1 \\
\hline 4 & NONE & NIL & Negative & Negative & 3.5 \\
\hline 5 & NONE & NIL & Negative & Negative & 3 \\
\hline 6 & NONE & NIL & Negative & Negative & 4 \\
\hline 7 & $1 \mathrm{C}$ & NIL & Negative & Positive & 3 \\
\hline 8 & $1 \mathrm{~B}, 1 \mathrm{C}, 2 \mathrm{~B}, 2 \mathrm{C}, 3 \mathrm{~B}, 4 \mathrm{~B}, 4 \mathrm{C}$ & NIL & positive & Positive & 2 \\
\hline 9 & NONE & NIL & Negative & Negative & 3 \\
\hline 10 & $3 \mathrm{~A}, 3 \mathrm{~B}, 4 \mathrm{~B}, 4 \mathrm{C}$ & NIL & Negative & Positive & 2 \\
\hline 11 & $1 \mathrm{~B}, 1 \mathrm{C}, 2 \mathrm{~A}, 2 \mathrm{~B}, 2 \mathrm{C}$ & NIL & Positive & Positive & 1.5 \\
\hline 12 & NONE & NIL & Negative & Negative & 3.5 \\
\hline 13 & $1 \mathrm{C}, 2 \mathrm{~A}, 2 \mathrm{~B}, 4 \mathrm{~B}$ & NIL & Negative & Positive & 2.5 \\
\hline 14 & $1 \mathrm{~B}, 2 \mathrm{~B}, 2 \mathrm{C}, 3 \mathrm{~B}, 3 \mathrm{C}$ & NIL & Positive & Positive & 0.5 \\
\hline 15 & NONE & NIL & Negative & Negative & 3.5 \\
\hline 16 & NONE & NIL & Negative & Negative & 4 \\
\hline 17 & $2 \mathrm{~A}, 2 \mathrm{C}, 3 \mathrm{~A}, 3 \mathrm{~B}, 3 \mathrm{C}, 4 \mathrm{~A}, 4 \mathrm{~B}, 4 \mathrm{C}$ & NIL & Negative & Positive & 2 \\
\hline 18 & NONE & NIL & Negative & Negative & 3.5 \\
\hline 19 & ALL & NIL & Positive & Positive & 0.5 \\
\hline 20 & $1 \mathrm{C}$ & NIL & Negative & Positive & 3.5 \\
\hline 21 & NONE & NIL & Negative & Negative & 4 \\
\hline
\end{tabular}




\begin{tabular}{|c|c|c|c|c|c|}
\hline Cases & Levels involved & Skip lesion & $\begin{array}{c}\text { Routine grossing } \\
\text { method }\end{array}$ & $\begin{array}{c}\text { Our grossing } \\
\text { method }\end{array}$ & $\begin{array}{c}\text { Tumour Areola } \\
\text { Distance (in } \mathbf{c m} \text { ) }\end{array}$ \\
\hline 22 & NONE & NIL & Negative & Negative & 4 \\
\hline 23 & 2C & NIL & Negative & Positive & 3.5 \\
\hline 24 & $1 \mathrm{~A}, 1 \mathrm{C}, 2 \mathrm{~B}, 2 \mathrm{C}, 3 \mathrm{~B}, 3 \mathrm{C}, 4 \mathrm{C}$ & NIL & Positive & Positive & 4 \\
\hline 25 & NONE & NIL & Negative & Negative & 2 \\
\hline 26 & 4C & NIL & Negative & Positive & 1.5 \\
\hline 27 & NC,4C & NIL & Negative & Positive & 6 \\
\hline 28 & NONE & NIL & Negative & Negative & 4 \\
\hline 29 & NONE & NIL & Negative & Negative & Negative \\
\hline 30 & NONE & NIL & Negative & N \\
\hline
\end{tabular}

Table 2: Chi -square method.

\begin{tabular}{|c|c|c|c|}
\hline & Routine grossing methodology & Extensive sampling technique & total \\
\hline Positive Nipple areolar involvement & 06 & 21 \\
\hline Negative Nipple areolar involvement & 24 & 15 & 39 \\
\hline Total & 30 & 30 & 60 \\
\hline
\end{tabular}

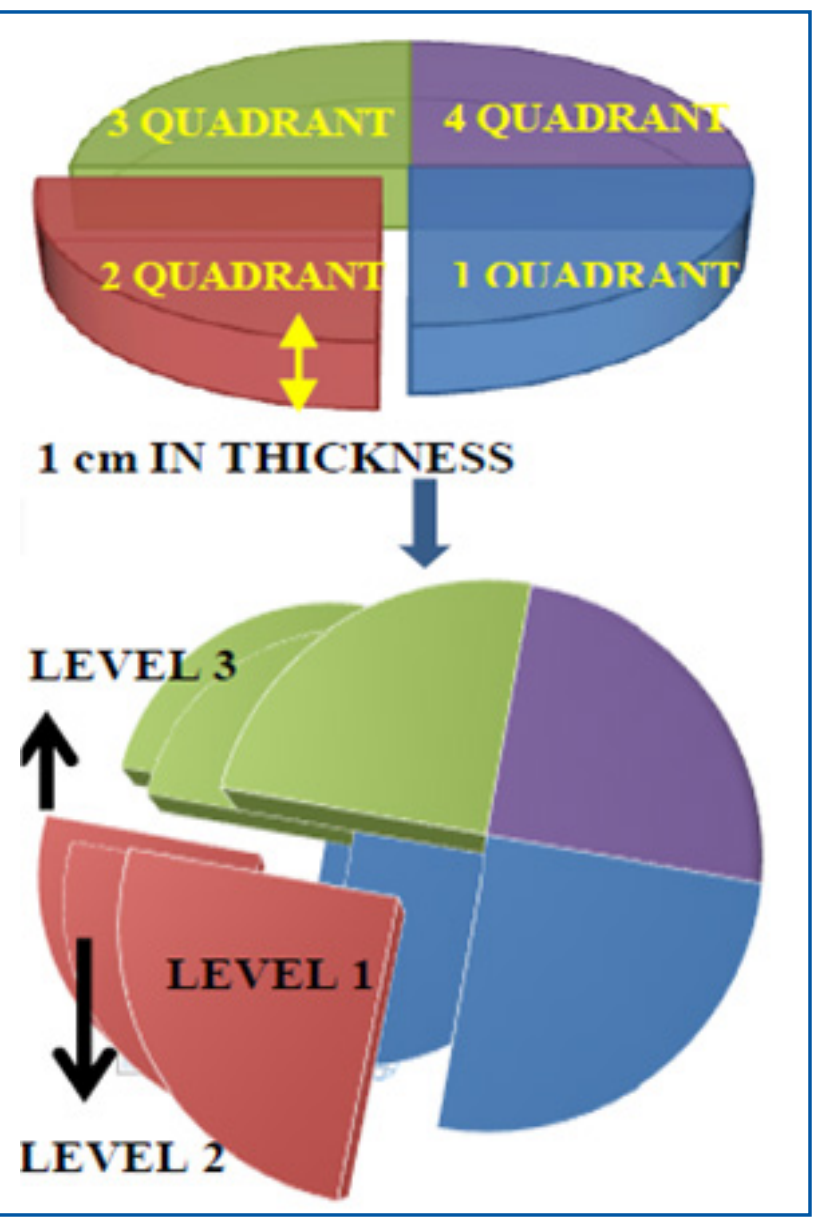

Fig. 1: Extensive sampling technique for nipple- areola complex.

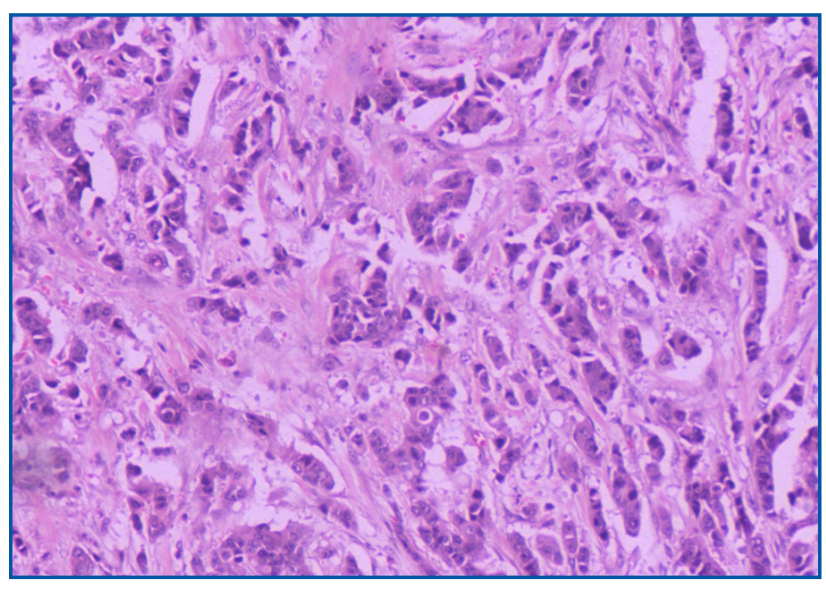

Fig. 2: Nipple areola section showing invasive carcinoma H/E 400X.

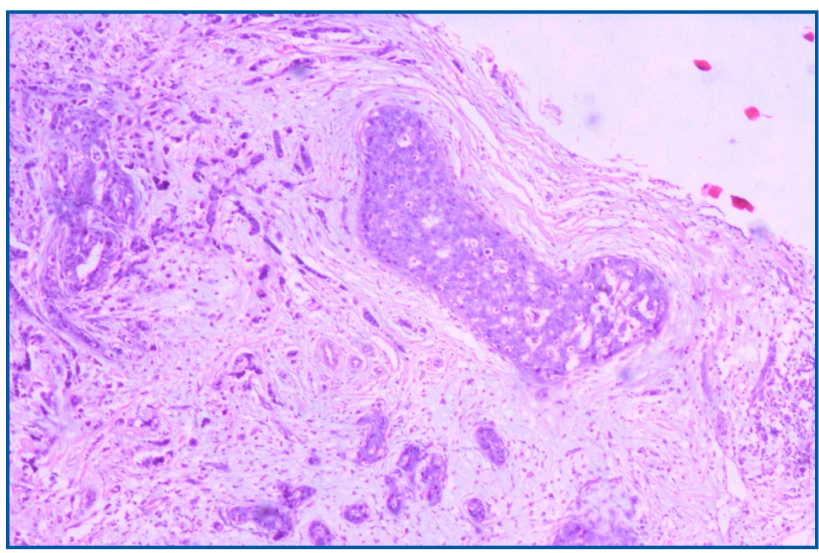

Fig. 3: Invasive carcinoma with intraductal component (arrow) H/E 400X. 


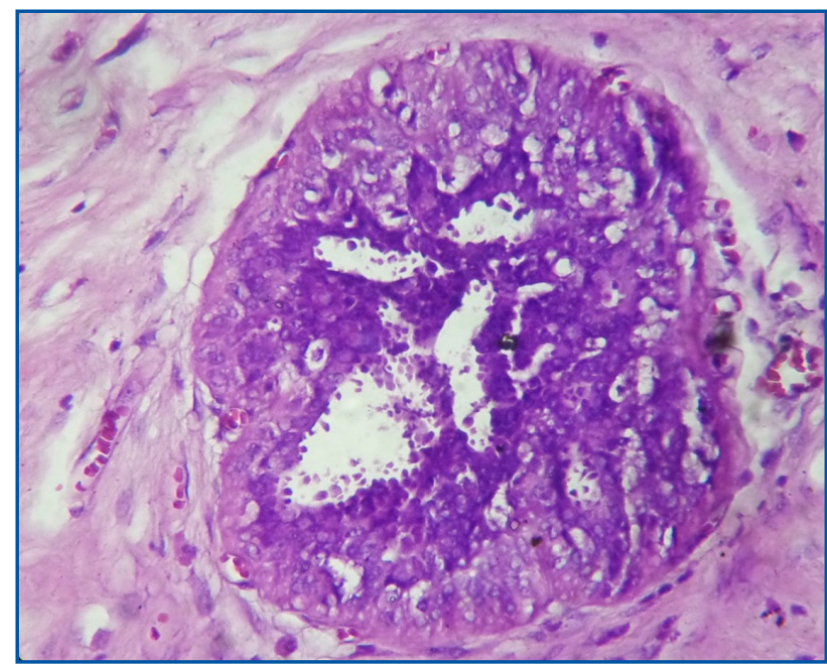

Fig. 4: Carcinoma in situ H/E 400X.

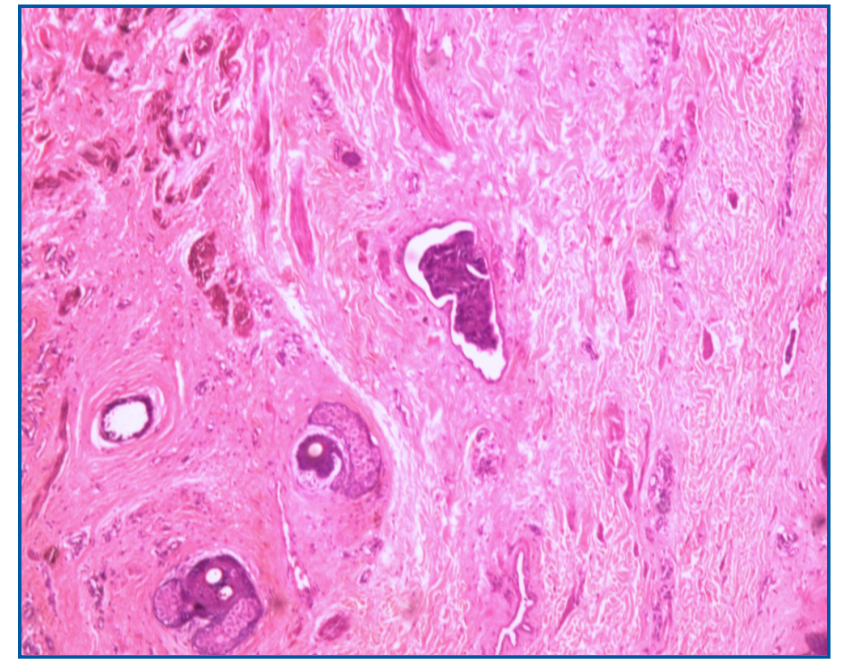

Fig. 5: Lymphatic embolus (arrow) H/E-100X.

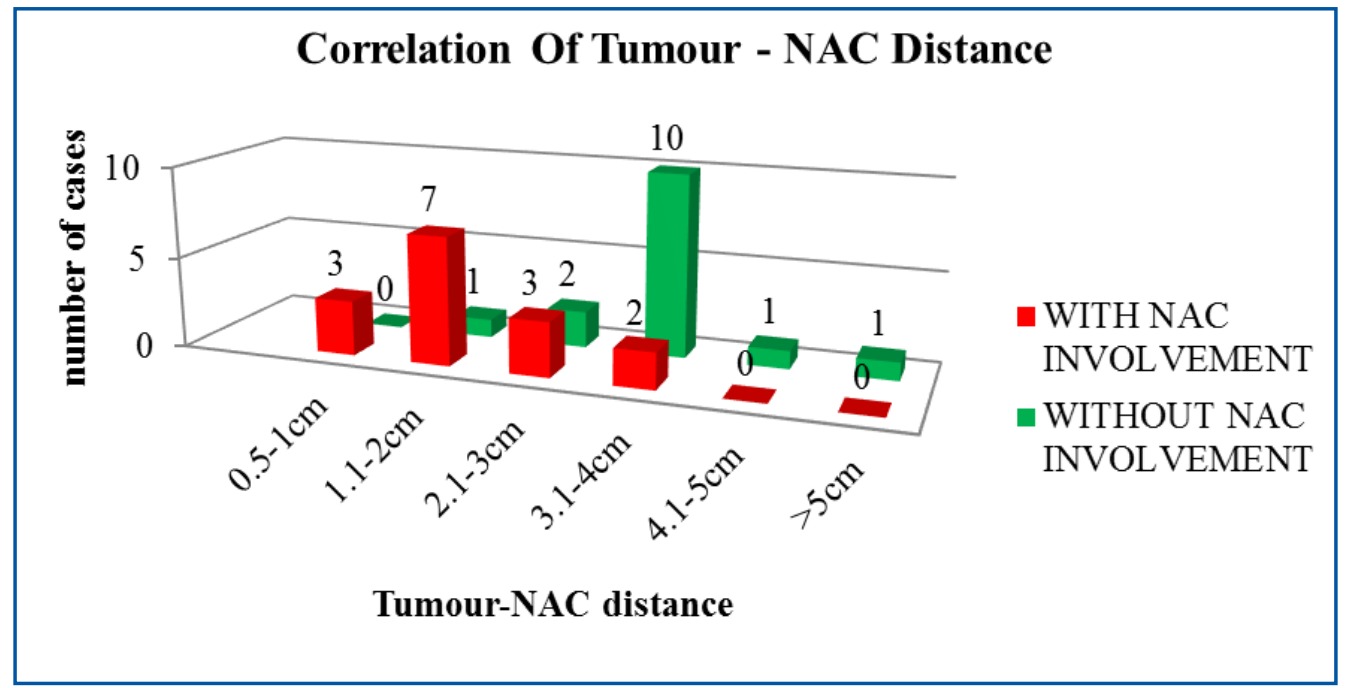

Fig. 6:

\section{Discussion}

In the present study cases with gross NAC involvement were excluded. So the cases with NAC involvement in our study were cases of occult nipple carcinoma, not evident clinically. NAC involvement was seen in 50\% of the cases, which represents clinically undetected load of NAC involvement. Anderson JA et al and Menon RS et al followed a extensive sampling techniques yielding higher percentages of NAC involvement $50 \%$ and $58 \%$ respectively. In both studies, multiple sections were taken both vertically and horizontally from $1 \mathrm{~cm}$ block of tissue from NAC region ${ }^{4,5}$

A study by Verma GR et al showed $0 \%$ NAC involvement, they had taken four sections from NAC at right angle to each other at different levels within the depth of $1 \mathrm{~cm} .{ }^{6}$ In Present study, we followed extensive sampling technique and our result of 50\% NAC involvement indicates the importance of sampling technique. The traditional one sagittal section is likely to underestimate NAC involvement compared to extensive sampling techniques. Our result of $50 \%$ NAC involvement correlated with the findings of Anderson et al and Menon et al, probably because extent of sampling has a huge effect on NAC findings.,

Santini et al, observed that the mechanism of spread of carcinoma breast to nipple areola can be of 3 types- direct extension, dissemination through ducts and lymphatics ${ }^{8}$. In a study done by Menon et al tumour was present in apparently unrelated manner. Skip lesion was seen in two cases. Base was involved in 10 cases either alone or in combination with other levels ${ }^{5}$. 
Simmons RM et al in their study analysed malignant involvement of areola and nipple separately, areolar involvement was detected in $<1 \%$ of patients and only in those with diffuse invasive carcinomas and multiple positive axillary lymph nodes. No patients with stage 0 , 1 or 2 breast carcinoma had areolar involvement. All patients with areolar involvement also had involvement of the nipple. So, they advocated use of areolar sparing mastectomy with surgical excision of the breast and nipple as a potential treatment for selected cases ${ }^{11}$.

In our study retroareolar level was most commonly involved followed by areolar level and nipple papilla was least involved and in almost all cases was involved along with deeper levels. Our study did not support areolar sparing mastectomy.

Brachtel EF et al in their study examined the retro areolar tissue for malignancy, they found that absence of carcinoma in retro areolar tissue correlates with the absence of carcinoma in the nipple with a sensitivity of 0.8 and negative predictability of 0.96 . They said detection of carcinoma in the retro areolar margin generally indicates the need for resection of the nipple whether or not the remainder of the nipple is found to be involved. They said a retro areolar en face margin may be used to test for occult nipple involvement in patients with nipple sparing mastectomy. ${ }^{12}$ Li W et al and Crowe JP et al in their study found that occult carcinoma most commonly involved the base of the nipple which was also observed in our study ${ }^{13,14}$.

In our study, retroareolar level was the most commonly involved (14/15 cases with NAC involvement). More than one level was involved in 9 cases. Areolar level was involved in $10 / 15$ cases. Nipple papilla was involved in 6/15 cases, and was always involved after the other 2 deeper levels. Skip lesion with involvement of only areolar level was seen in one case(table-1).

In our study, as the Tumour - NAC distance decreased, involvement of NAC was significant. P- value was 0.010 and there was a statistically significant correlation between Tumour-NAC distance in $\mathrm{cm}$ and NAC involvement (fig-6).

\section{Conclusion}

If Only gross involvement of nipple is taken into consideration large amount of occult NAC involvement will be missed out. Extensive sampling technique improves the pick up rate of nipple areolar involvement in carcinoma breast. The traditional one sagittal section underestimates nipple areolar involvement compared to extensive sampling technique. Tumour - Nipple areolar distance being the most important predictor of nipple areolar involvement there is a need to follow extensive sampling methodology atleast in cases with significantly less Tumour- NAC distance.

Possibility of skip lesion can lead faulty negative reporting if routine grossing methodology is followed and should keep the pathologist alerted, though the frequency of skip lesion is rare. Retroareolar tissue examination can give a clue as to whether nipple papilla is involved or not as usually it is the first level to be involved before areolar and nipple papilla.

Further studies are needed to support the findings of this study as the sample size was a limiting factor. Follow up of the cases were not done in our study and further studies are needed to determine the recurrence risk in carcinoma breast cases.

\section{Acknowledgements}

Faculty, friends, and family members have helped us to complete this study. Timely technical help was provided by technicians of histopathology section of the department of pathology.

\section{Reference}

1. WHO page. http://www.who.int/cancer/detection/ breastcancer/en/ (accessed march 13,2017)

2. World cancer research fund international page. http://www. wcrf.org/int/cancer-facts-figures/data-specific-cancers/ breast-cancer-statistics (accessed march 13, 2017)

3. Smith J, Payne WS, Carney JA. Involvement of Nipple and Areola in Carcinoma of the Breast. Surg Gynecol Obstet 1976;143:546-8.

4. Andersen JA, Gram JB, Pallesen RM. Involvement of the nipple and areola in breast cancer. Value of clinical findings. Scand J Plast Reconstr Surg 1981;15(1):39-42.

5. Menon RS, Geel ANV . Cancer of breast with nipple involvement. Br journal of cancer 1989;59:81-4

6. Verma GR, Kumar A, Joshi K. Nipple involvement in peripheral breast carcinoma :a prospective study. Indian Journal of Cancer 1997;34:1-5.

7. Millard DR, Devine J, and Warren WD. A Plea for Saving the Uninvolved Nipple. Am J Surg 1977;122:763.

8. Santini D, Taffurelli M, Gelli MC, Grassigli A, Giosa F et al: Neoplastic involvement of nipple-areolar complex in invasive breast cancer. Am J Surg 1989; 158:399-403

9. Grossing (histologic sampling) of breast lesions. Pathology Outlines.com website.http://www.pathologyoutlines.com/ topic/breastmalignantgrossing.html. (Accessed March 13th, 2017).

10. UCM gross pathology. The university of Chicago. https:// grosspathology-sites.uchicago.edu/page/mastectomy (Accessed March 13 th 2017). 
11. Simmons RM, Brennan M, Christos P, King V, Osborne M. Analysis of nipple/areolar involvement with mastectomy: can the areola be preserved? Ann Surg Oncol 2002; 9: 165-8

12. Brachtel EF, Rusby JE, Michaelson JS, Chen LL, Muzikansky A et al. Occult nipple involvement in breast cancer :clinicopathologic findings in 316 consecutive mastectomy specimens. J Clin Oncol. 2009;27:4948-54
13. Li W, Wang S, Guo X, Lang R et al. Nipple involvement in breast cancer: retrospective analysis of 2323 consecutive mastectomy specimens. Int J Surg Pathol 2011;19:328-334

14. Crowe JP, Kim JA, Yetman R, Banbury J , Patrick RJ et al: Nipple-sparing mastectomy : Technique and results of 54 procedures. Arch Surg 2004 ; 139: 148-150

*Corresponding author:

Dr Sumanashree Mallappa "Malayashree Nilaya" 2 cross, 1B main, Nagarbhavi village, Bangalore -560072, India

Phone: +91 9990476487

Email: kusumadallisumana@gmail.com

Financial or other Competing Interests: None. 